\title{
Recerca geològica i mineralògica per la comarca del Ripollès: des de Ribes de Freser a Planoles, Espinosa i a Toses
}

Josep Maria Mata-Perelló

Joaquim Sanz Balagué

\section{XARAGALL \\ REVISTA DE CIÈNCIES DE LA CATALUNYA CENTRAL}

\section{ก. 6}

JUNY 2014 


\section{RECERCA GEOLÒGICA I MINERALÒGICA PER LA COMARCA DEL RIPOLLÈS: DES DE RIBES DE FRESER A PLANOLES, ESPINOSA I A TOSES}

\section{Josep Maria Mata-Perelló}

Museu de geologia Valentí Masachs, Escola Politècnica Superior d'Enginyeria de Manresa (EPSEM), Universitat Politècnica de Catalunya · BarcelonaTech (UPC), 08272 Manresa, Spain

\section{Joaquim Sanz Balagué}

Departament d'Enginyeria Minera i Recursos Naturals (EMRN), Escola Politècnica Superior d'Enginyeria de Manresa (EPSEM), Universitat Politècnica de Catalunya - BarcelonaTech (UPC), 08272 Manresa, Spain

Paraules clau: Sistema Pirinenc; Materials paleozoics; Materials volcànics

\section{Resum}

Itinerari realitzat el 2 de juny de 2013. En aquesta ocasió, el recorregut de l'itinerari discorrerà en la totalitat pel Sistema Pirinenc, i més concretament pel sector dels Pirineus Orientals. Dintre d'aquests, deambularà per tres dels seus sectors més representatius: en concret per la zona dels anomenats Apilaments Antiformes del Freser i també per la Zona Axial, pròpiament dita. Així, el recorregut s'iniciarà dintre de l'esmentada zona dels Apilaments Antiforms del Freser, la qual es transitarà fins poc després de Ribes, en arribar a l'Encavalcament de RibesCamprodon. Finalment, els darrers trams del recorregut de l'itinerari, ja s'efectuaran per la Zona Axial, en la qual clourà el recorregut, en arribar a Planès de Rigart i a Toses.

També cal dir, per d'altra banda, que la totalitat del recorregut, del present itinerari, es desenvoluparà per dintre de la superfície ocupada per la comarca del Ripollès, la qual pertany a la Regió de Vic. 


\section{Objectius fonamentals}

Els objectius fonamentals que es pretenen aconseguir en aquest itinerari geològic i mineralògic, són els següents:

1. Observació i estudi dels afloraments del Sistema Pirinenc, tant als Apilaments Antiformes del Freser o com els de la Zona Axial, els quals anirem trobant a diferents indrets al llarg de tot el recorregut de l'itinerari.

2. Observació i estudi dels materials paleozoics (fonamentalment del Cambro-Ordovicià i de I'Ordovicià), que constitueixen tant els afloraments dels Apilaments Antiformes del Freser, com els de la Zona Axial. Aquests materials els tallarem pels voltants de Ribes de Freser $\mathrm{i}$ entre aquesta població i la de Toses.

3. Estudi i descripció de les relacions i els contactes existents entre les unitats acabades d'esmentar al paràgrafs anteriors, i també entre els materials que les constitueixen. Així, ens referirem al denominat encavalcament de Ribes - Camprodon. el qual constitueix el límit septentrional dels Apilaments Antiformes de Ribes.

4. Observació i reconeixement dels materials volcànics, si s'escau, que es troben entre els afloraments de I'Ordovicià (dintre dels Apilaments Antiformes de Ribes). Aquests afloraments es troben constituïts per riolites i granòfids (els denominats "granòfids de Ribes").

5. Estudi i descripció de diferents mineralitzacions, que anirem veient al llarg de tot el recorregut, com les següents:

A) de les mineralitzacions filonianes d'antimoni i d'arsènic, situades als termes de Ribes de Freser, Planoles i també a Planès de Rigart, entre molts altres indrets de la comarca del Ripollès. Encaixen sempre entre els materials de l'Ordovicià.

B) Observació de les mineralitzacions filonianes de coure, situades al terme de Planoles, al Pla de les Cabanes. Com les anteriors, encaixen sempre entre els materials de I'Ordovicià.

C) Observació de mineralitzacions ferruginoses, relacionades amb zones d'oxidació, que trobarem prop de Ventolà, en unes antigues explotacions de ferro, les quals es relacionaven amb unes fargues.

6. Observació de diferents explotacions mineres, relacionades amb les mineralitzacions acabades d'esmentar.

7. Observació del diferents elements, relacionats amb el patrimoni geològic i miner, que anirem trobant al llarg del recorregut.

\section{Antecedents}

$\mathrm{Hi}$ ha alguns antecedents, relatius a itineraris geològics i mineralògics, el quals discorren per indrets propers al present. Entre aquests, farem esment de diversos treballs nostres, com els següents: Mata-Perelló (1995, 1996a, 1996b, 1996c, 1997a, 1997b, 1998, 2007, 2011a i 2011b). També farem esment de dos treballs més, on hi ha itineraris coincidents parcialment amb el present. Es tracta de: Mata-Perelló i Font Soldevila (1995), i de Mata-Perelló i Sanz Balagué (1991). 
Pel que fa a les mineralitzacions que veurem en aquest itinerari, cal dir que ja estat prèviament descrites per nosaltres en un altre treball (d'àmbit general referit al conjunt de Catalunya), al qual ens remetin. Es tracta de Mata-Perelló (1991).

Per d'altra banda, en canvi, farem esment de diversos treballs, de caràcter geològic general $\mathrm{i}$ regional, com són els següents: Guimerà et altri (1992), i RIBA et altri (1976). Tanmateix, i pel que fa a les monografies regionals, farem esment dels treballs: IGME (1991 i 1994).

Tots aquests treballs, figuren convenientment referenciats, per estricte ordre alfabètic, dintre de I'apartat dedicat a les REFERÈNCIES BIBLIOGRÀFIQUES, al qual ens remetin.

\section{Recorregut de l'itinerari}

El recorregut de l'itinerari, s'iniciarà a la població de Ribes de Freser. Després des d'ella, el recorregut farà una fillola, i es dirigirà cap a Campelles, per tal d'anar cap a les Mines de Sant Antoni, on es farà una nova aturada. Posteriorment, després de retornar a Ribes de Freser, I'itinerari continuarà cap a Planés de Rigart, seguint la carretera N - 152. Tot i així, abans d'arribar-hi, es farà una fillola, per tal d'anar cap a Ventolà, des d'on s'anirà cap a les Mines de Can Paloca, on es farà una aturada.

Després, es retornarà a la carretera $\mathrm{N}-152$, amb la intenció d'arribar a Planoles, des d'on s'iniciarà una nova fillola, per tal d'anar cap a les mines del Pla de les Cabanes, on es farà una altra parada. Després, es retornarà de nou a Planoles, des d'on s'anirà cap al poble veí de Planès de Rigart, i cap a les Mines $d^{\prime}$ Espinosa, on es farà la una nova aturada del present itinerari. Tot i així, el recorregut es perllongaria fins a Toses, per on finalitzaria.

\section{Advertiments previs}

Com en altres recorreguts de RECERCA GEOLÒGICA I MINERALÒGICA ..., semblants al present, si es disposa del temps suficient, poden efectuar-se passant per totes les parades $\mathrm{i}$ filloles indicades al present guió. En cas contrari, recomanem prescindir de les anomenades PARADES - CONDICIONALS.

Cal dir també, que en aquest itinerari ens trobarem devent de tres trams de camins forestals en molt mal estat de conservació; per la qual cosa serà molt millor transitar a peu per ells.

En qualsevol cas, cal tenir sempre una cura molt especial de respecte a la natura, al llarg de tot el recorregut; de l'itinerari.

\section{Descripció de l'itinerari}

Com de costum, estructurarem el recorregut de l'itinerari en una sèrie de PARADES (o d'ESTACIONS), que tot seguit anirem veient. En cadascuna d'aquestes aturades farem un breu comentari (geològic o mineralògic, segons s'escaigue). Per d'altra banda, en cada cas indicarem, entre parèntesi, el full topogràfic on es troba l'aturada. Per d'altra banda, en cadascuna de les parades, indicarem entre parèntesi el número del "Mapa Topográfico", a 
escala 1:50.000, on es troba situada la parada considerada. Finalment, cal dir que el recorregut de l'itinerari s'inclourà dintre dels següents fulls: $\mathbf{2 1 7}$ (dit de Puigcerdà), $\mathbf{2 5 5}$ (dit de la Pobla de Lillet) i 256 (o de Ripoll). Així doncs, la relació general de les parades que constitueixen aquest itinerari, és la següent:

\subsection{Parada 1. MINES DE SANT ANTONI, (terme municipal de Ribes de Freser, comarca del Ripollès). (Full 256).}

El recorregut l'iniciarem a la població de Ribes de Freser, situada al peu de la carretera nacional N-152. Després, ens caldrà anar cap a I'Estació, per tal d'agafar la carretera local que es dirigeix cap a Campelles, la GiV-4011, amb la finalitat de fer una fillola en arribar al collet de la Casassa, d'on surt un camí per la dreta, el qual ens conduirà fins a l'Ermita de Sant Antoni. Prop d'aquest indret, hi ha unes mines, on es farà la present aturada. Així, des de la parada anterior, haurem efectuat un recorregut proper als $66 \mathrm{Km}$, aproximadament, des de l'inici del recorregut

A partir del seu inici el recorregut, s'efectua entre els materials esquistosos i pissarrencs de I'Ordovicià, els quals situats a la zona d'Apilaments Antiformes del Freser. Entre aquests materials, cal fer esment de la presència del granòfir de Ribes, el qual es troba prop de l'ermita de Sant Antoni, al Nord de la mateixa.

En aquest indret, hi ha una mineralització filoniana, la qual es troba encaixada entre els esquistos de I'Ordovicià. Entre els minerals primaris presents, cal fer esment dels següents: AESENOPIRITA, BETHIERITA (indicis), CALCOPIRITA, ESTIBINA (és el mineral més abundant), GALENA, JAMESONITA, PIRITA, TETRAEDRITA, CALCITA i QUARS.

Entre els minerals d'alteració, cal fer esment dels següents: CERVANTINITA, GOETHITA (terrosa i limonítica), HEMATITES, VALENTINITA, ATZURITA (indicis), MALAQUITA i GUIX. També cal fer esment de la presencia de PIROLUSITA (dendrítica).

En aquest indret, es van realitzar diverses explotacions mineres, generalment poc importants. A I'actualitat es troben força enrunades, i es molt dificultós trobar els filons. (fotografia 1).

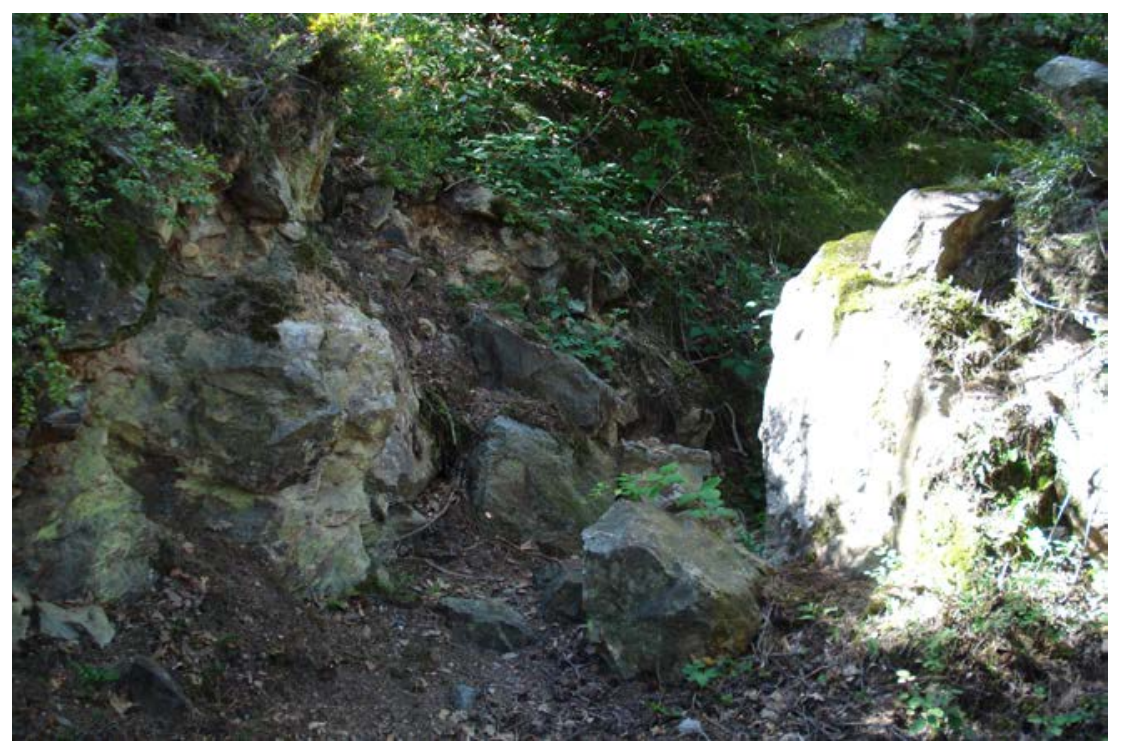

Fotografia1. Una de les antigues explotacions 


\subsection{Parada 2 - CONDICIONAL. MINES DE FERRO DE CAN PALOCA, (Ventolà, terme de Ribes de Freser, comarca del Ripollès). (Full 255).}

Des de la parada anterior, cal retornar enrere, per tal d'arribar de nou a Ribes de Freser. Posteriorment, des d'aquest poble, haurem de de seguir la carretera $\mathrm{N}-152$, la qual va remuntant el riu Rigart (afluent a Ribes del riu Fesser). Més endavant. En arribar al trencall de d'on surt la carretera local GiV-5218, la qual es dirigeix cap a Ventolà. Nosaltres I'haurem d'agafar, però poc abans d'arribar al poble, ens caldrà seguir a peu, per un camí que surt per la dreta, amb la intenció de fer una fillola que ens haurà de conduir cap a les Mines de Ferro de Can Paloca. Aquí, en arribar-hi, farem la present aturada, després de fer un recorregut proper als $14 \mathrm{Km}$, des de la parada anterior, dels quals $1^{\prime} 5 \mathrm{Km}$, els haurem fet a peu.

Tot aquest recorregut, s'ha efectuat íntegrament entre els nivells de lutites i ritmites de I'Ordovicià, les quals alternen amb nivells de calcàries i de dolomies. Precisament, en aquest indret, hi ha una mineralització desenvolupada sobre aquests darrers materials.

La mineralització, consisteix en la concentració d'abundants òxids de ferro, amb presència de: GOETHITA (limonítica i terrosa), HEMATITES (terrosa) i LEPIDOCROCITA (d'un aspecte similar al de la goethita). Aquests minerals, s'han format a partir de l'oxidació de sulfurs primaris, com ARSENOPIRITA i PIRITA, fonamentalment, les quals també es troben presents a I'indici.

Per d'altra banda, també es troben presents altres minerals, com els següents: PIROLUSITA (la qual es presenta sempre terrosa i també dendrítica), CALCITA, SIDERITA i QUARS.

Aquesta mineralització va ésser explotada, per a l'obtenció dels minerals de ferro; tot i així, darrerament ha estat investigada, de cara a la prospecció dels indicis d'OR NADIU que es troben al lloc de l'indici, entre els esmentats oxids de ferro, tot formant part de la zona d'oxidació, formada a partir de l'alteració dels sulfurs primaris, entre els quals es trobava l'esmentat or nadiu.

\subsection{Parada 3. PLA DE LES BARRAQUES, (terme municipal de Planoles, comarca del Ripollès). (Full 217).}

Des de la parada anterior, cal retornar enrere, fins a la carretera $N$ - 152. En arribar-hi, ens caldrà seguir cap Planoles. Més endavant, en trobar per la dreta la carretereta que condueix cap el Pla de les Cabanes, ens caldrà agafar-la. En arribar-hi farem una nova aturada, després de recórrer uns $14 \mathrm{Km}$.

En tot aquest recorregut, s'han anat tallant els nivells esquistosos de l'Ordovicià. I aquests nivells són, precisament els materials que apareixen en aquest indret. Aquí, hi ha unes mineralitzacions filonianes, les quals no arriben a aflorar (en trobar-se cobertes pels derrubis). Tot i així, pot dir-se que aquests filonets encaixen entre els materials de la Formació Jujols, que són els que afloren en aquests indrets del coll.

Per d'altra banda, en aquest indret, van realitzar-se unes explotacions de les mineralitzacions anteriors, les quals es troben enrunades, per la qual cosa, tampoc són visibles les mineralitzacions a l'interior de les mines. (fotografia 2).

Entre els minerals primaris, els quals es troben a les escombreres, cal fer esment de la presència d'ARSENOPITA, CALCOPIRITA, ESTIBINA i PIRITA. També es troben la CALCITA, i sobretot el QUARS. Per d'altra banda, entre els minerals d'alteració, es troben: GOETHITA (terrosa i limonítica), HEMATITES (terròs, com I'anterior), ATZURITA, MALAQUITA, 
CALCANTINA, GUIX i MELANTERITA. Tanmateix es troben també indicis de CUPRITA i de TENORITA. També cal dir que hi ha presència de PIROLUSITA (dendrítica).

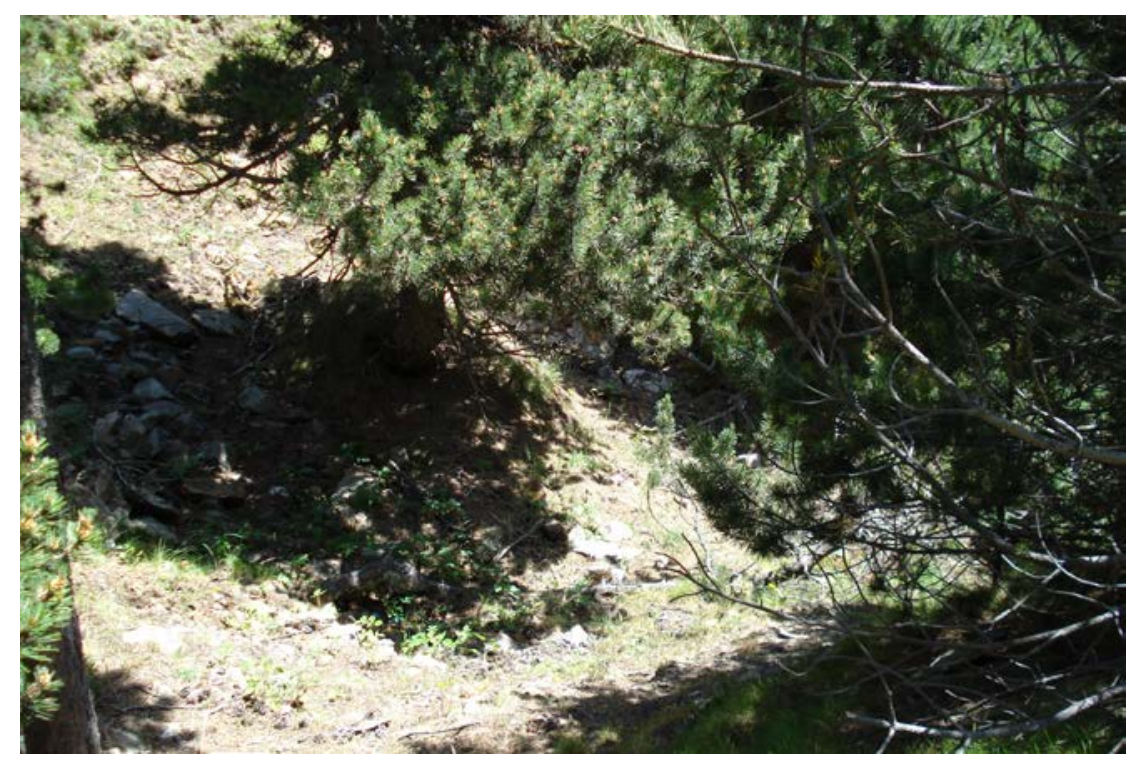

Fotografia 2. Zona Minera del Pla de les Cabanes

\subsection{Parada 4. MINES D’ESPINOSA, (Espinosa, terme municipal de Toses, comarca del Ripollès). (Full 255).}

Des de la parada anterior cal tornar enrere, per tal de retornar cap a Planoles. Després, des d'aquest poble, ens caldrà continuar per la mateixa carretera que es va seguint, la N-152, fins arribar al proper poble de Planès de Rigart. Tot seguit, des d'aquest, ens caldrà agafar el camí-carretera que condueix cap a Toses, el qual es seguirà fins arribar ben a prop del poblet d'Espinosa. Poc abans d'arribar-hi, es troben les Mines d'Espinosa, on cal efectuar la present aturada. Així, des de la parada anterior, en caldrà efectuar un recorregut proper als $11 \mathrm{Km}$.

En tot aquest recorregut, s' han anat tallant els nivells de lutites i de ritmites de l'Ordovicià, les quals es situen dintre de la Zona Axial, per on anem circulant des de la sortida de Ribes de Freser, tot anant cap a Rialb i cap a Queralbs, en el trajecte cap a la PARADA 4, en el qual hem sobrepassat I'Encavalcament de Ribes-Camprodon.

En aquest lloc hi ha unes mineralitzacions filonianes, encaixades entre els materials de la Formació Jujols. Els minerals primaris presents són: ARSENOPIRITA (molt abundant), CALCOPIRITA, ESTIBINA, PIRITA, CALCITA i QUARS.

I, entre els minerals d'alteració, formats a partir dels anteriors, es troben: CERVANTINITA, GOETHITA (terrosa i limonítica), HEMATITES. MINI (indicis), ATZURITA, MALAQUITA, SIDERITA i GUIX. Per d’altra banda, també hi ha: PIROLUSITA (dendrítica).

Finalment, també cal dir que entre l'arsenopirita hi ha indicis d'OR NADIU, i que en successives etapes històriques, aquest or ha estat motiu de prospecció, i inclòs d'explotació. (fotografia 3). 


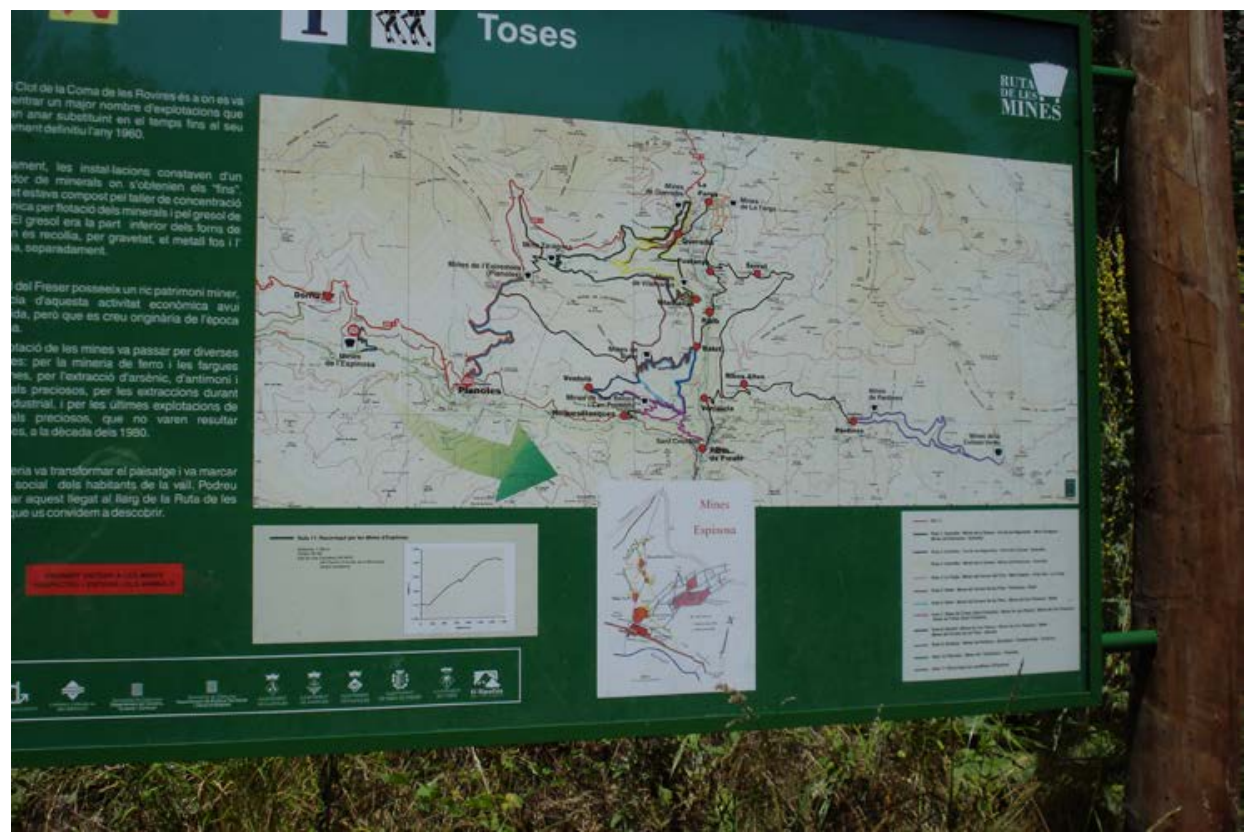

Fotografia 3. Cartell explicatiu de les mines de la Vall de Ribes. Es troba situat al costat de la destruïda Mina Espinosa

Després de fer-se aquesta aturada., el recorregut pot continuar per la Vall de Rigart, arribant finalment a Toses i a la Collada de Toses.

En aquest indret finalitza el recorregut de l’itinerari.

\section{Bibliografia}

GUIMERÀ, J. et altri (1992).- Geologia (II), Història Natural dels Països Catalans. Vol. 2, 547 pag. Enciclopèdia Catalana, S.A., Barcelona.

IGME (1991).- Mapa Geológico de España a escala 1:50.000 (síntesis de la cartografia existente). Full i memòria número 256 (Ripoll). Inst. Tecnol. y GeoMinero de España, Minist Indústria. Madrid.

IGME (1994).- Explicació del Mapa Geologico de España, a escala 1:50.000. Full i memòria número 255 (la Pobla de Lillet). Inst. Tecnol. y GeoMinero de España. Minist. Indústria. Madrid.

MATA-PERELLÓ, J.M. (1991).- Els Minerals de Catalunya. Arxius de la Secció de Ciències, t. XCIII, 442 pag. Institut d’Estudis Catalans. Barcelona. 
MATA-PERELLÓ, J.M. (1995).- Recerca a través de la geografia física de set comarques de la Catalunya Central. Pub. Museu de Geologia de la UPC, 168 pàgines. Manresa.

MATA-PERELLÓ, J.M. (1996a).- Selecció d'itineraris geològics i mineralògics pel Berguedà, i per les seves comarques veïnes. Pub. Universitat Catalana d'Estiu de la Natura. 52 pàgines. Berga.

MATA-PERELLÓ, J.M. (1996b).- Itinerari geològico-mineralògic per les comarques del Ripollès i de la Garrotxa: des de Campdevànol a Olot i a les Preses. Inèdit, 12 pàgines, Manresa

MATA-PERELLÓ, J.M. (1996c).- Recerca geològica i mineralògica per la comarca del Ripollès: des de Campdevànol a Sant Joan de les Abadesses, Surroca de Baix, Ribes de Freser i Planoles. Inèdit, 10 pàg. Manresa

MATA-PERELLÓ, J.M. (1997a).- Recerca geològica i mineralògica pel Berguedà i pel Ripollès: des de Berga a La Nou i Malanyeu, i des de la Pobla de Lillet a Campdevànol. Inèdit, 9 pàgines. Manresa

MATA-PERELLÓ, J.M. (1997b).- Recorregut de recerca geològica i mineralògica per les comarques del Berguedà i del Ripollès: des de la Pobla de Lillet a Castellar de N'Hug, a Ribes de Freser i a Queralbs. Inèdit. 10 pàgines. Manresa

MATA-PERELLÓ, J.M. (1998).- Recerca geològica i mineralògica per la comarca del Ripollès: des de Campdevànol a Ribes de Freser, Queralbs i a Planès de Rigart. Inèdit. 11 pag. Manresa

MATA-PERELLÓ, J.M. (2007).- Recerca geológica y mineralógica per la comarca del Ripollès: des de Casmpdevànolol a Ribes de Freser, Queralbs, Planoles i Toses. Inèdit. 12 pag. Manresa

MATA-PERELLÓ, J.M. (2011a).- Recerca geològica i mineralògica per la comarca del Ripollès: des de Campdevànol a Ribes de Freser, Queralbs, Planoles i a Toses. Inèdit. 12 pàgines. Manresa

MATA-PERELLÓ, J.M. (2011b).- Recerca geològica i mineralògica per la comarca del Ripollès: des de Ribes de Fresser a Planoles i a Toses. Inèdit. 8 pàgines. Manresa

MATA-PERELLÓ, J.M. i FONT SOLDEVILA, J. (1995).- Itinerari geològic-mineralògic pel Berguedà. Apunts EUPM, 78 pag. Barcelona.

MATA-PERELLÓ, J.M. i SANZ BALAGUÉ, J. (1991).- Guia de determinació dels minerals. Països Catalans i Altres. Edic. Parcir. Manresa.

RIBA ARDERIU, O. Et altri. (1976).- Geografia física dels Països Catalans. Edit Ketres. Barcelona 